\title{
The impact of subclinical hypothyroidism on long-term outcomes in older patients undergoing percutaneous coronary intervention
}

Yong-Sheng Liư ${ }^{1}$, Mei Wei ${ }^{1}$, Le Wang ${ }^{2}$, Gang Liu', Guo-Ping Ma', Katsushige Ono ${ }^{3}$, Ze-Long Cao ${ }^{1}$, Man Yang ${ }^{1}$ and Ming-Qi Zheng ${ }^{1 *}$

\begin{abstract}
Background: Subclinical hypothyroidism $(\mathrm{SCH})$ is reportedly associated with an increased risk of adverse events in patients undergoing percutaneous coronary intervention ( $\mathrm{PCl}$ ). The prognostic significance of SCH in the elderly was poorly defined. The purpose of this study was to evaluate the association between SCH and long-term outcomes in older patients undergoing $\mathrm{PCl}$.

Methods: Three thousand one hundred sixty-eight patients aged 65 years or older who underwent $\mathrm{PCl}$ from January 2012 to October 2014 were included. Patients were divided into SCH group $(n=320)$ and euthyroidism (ET) group $(n=2848)$ based on thyroid function test. Cox proportional hazard regression analyses were used to estimate the relative risks (RRs) of all-cause death and cardiac death for patients with SCH during a 4-year follow-up period.

Results: There were 227 deaths during the follow-up period including 124 deaths caused by cardiac events. There was no significant difference in mortality rate between the SCH group and the ET group $(p>0.05)$. After adjustment for covariates, compared with patients with ET, the RRs of death from all-cause and cardiac in patients with SCH were 1.261 (95\%Cl: $0.802-1.982, p=0.315)$ and 1.231 (95\%Cl: $0.650-2.334, p=0.524)$, respectively. When SCH was stratified by age, gender, and degree of thyroid-stimulating hormone elevation, no significant associations were also found in any stratum.
\end{abstract}

Conclusion: Our investigation revealed that $\mathrm{SCH}$ was negatively associated with the outcome of $\mathrm{PCl}$ in older patients.

Keywords: Subclinical hypothyroidism, Mortality, Older, Percutaneous coronary intervention

\section{Background}

Nowadays elderly patients receiving the percutaneous coronary intervention (PCI) represent more than one in five patients treated with PCI in real-world practice [1]. Mortality remained markedly higher in elderly patients

\footnotetext{
* Correspondence: mengqizheng1979@163.com

${ }^{1}$ Heart Center, The First Hospital of Hebei Medical University, No.89 Donggang Road, Shijiazhuang 050031, Hebei, China

Full list of author information is available at the end of the article
}

than those in younger counterparts after PCI [2]. The prediction of death after PCI is a challenging task for clinicians. To further improve the prognosis of elderly patients after PCI, significant attention has been paid to identify modifiable risk factors of mortality.

Increased risk of cardiovascular diseases including atherosclerosis are found among subclinical hypothyroidism $(\mathrm{SCH})$ patients, whose thyroid hormone levels remain normal and only thyroid-stimulating hormone (TSH)

(c) The Author(s). 2021 Open Access This article is licensed under a Creative Commons Attribution 4.0 International License, which permits use, sharing, adaptation, distribution and reproduction in any medium or format, as long as you give appropriate credit to the original author(s) and the source, provide a link to the Creative Commons licence, and indicate if changes were made. The images or other third party material in this article are included in the article's Creative Commons licence, unless indicated otherwise in a credit line to the material. If material is not included in the article's Creative Commons licence and your intended use is not permitted by statutory regulation or exceeds the permitted use, you will need to obtain permission directly from the copyright holder. To view a copy of this licence, visit http://creativecommons.org/licenses/by/4.0/ The Creative Commons Public Domain Dedication waiver (http://creativecommons.org/publicdomain/zero/1.0/) applies to the data made available in this article, unless otherwise stated in a credit line to the data. 
levels are increased. Some studies suggest that $\mathrm{SCH}$ is associated with hypercholesterolemia and atherosclerosis, and it should be an independent risk factor for atherosclerosis and myocardial infarction. Besides these, Thyroid hormones have other different effects on the cardiovascular system. Subclinical hypothyroidism $(\mathrm{SCH})$ has been associated with unfavorable effects, such as worsening blood pressure [3], atherogenic dyslipidemia [4], impaired cardiac contractile and diastolic function [5], increased systemic vascular resistance [6], endothelial dysfunction [6], accelerated atherosclerosis [7], enhanced inflammation level [8], hypercoagulability, insulin resistance and oxidative stress [7], all of which may increase the risk of death. Up to $10 \%$ of the elderly have $\mathrm{SCH}$, which is usually asymptotic [9]. The high prevalence of $\mathrm{SCH}$ in the elderly has led to a significant body of research concerning the possibility that $\mathrm{SCH}$ may herald mortality. However, current evidence on the association between $\mathrm{SCH}$ and mortality in the elderly are conflicting [10-14].

To date, reliable information on the association between $\mathrm{SCH}$ and mortality in older patients with coronary artery disease is limited. Whether $\mathrm{SCH}$ contributes to mortality in elderly patients undergoing PCI remains unclear. Therefore, to further examine the association between SCH and risk of all-cause as well as cardiac mortality in elderly patients, we evaluate the effect of $\mathrm{SCH}$ on mortality rate in patients aged 65 years or older who underwent PCI in a single high-volume center.

\section{Methods}

\section{Study population and follow-up}

This was a retrospective cohort study from January 2012 to October, 2014. We evaluated 4968 consecutive patients aged 65 years or older who underwent PCI and thyroid function examination at First Affiliated Hospital of Hebei Medical University. The following patients were excluded from the study: 106 patients with missed thyroid function test results; 171 patients with a thyroid disease or treated with anti-thyroid drugs; 204 patients treated with amiodarone; 23 patients with malignant disease; 240 patients with overt hypothyroidism or hyperthyroidism; 209 patients with subclinical hyperthyroidism; 847 patients with low triiodothyronine syndrome. Thus, the final cohort included 3168 patients. All the patients' information was obtained by independent reviewers who were blind to the purpose of the study. All clinical, laboratory, medication and PCI data were collected. Clinical follow-up was performed by either telephone contact or office visit. All the patients were prospectively followed up for 4 years and the follow-up rate was $90.1 \%$. The end point of this study was all-cause mortality and cardiovascular disease (CVD)-related death. Causes of death were determined by medical records, death certificates and autopsy reports. All the patients in the retrospective study gave written informed consent (Fig. 1).

\section{Thyroid function testing}

Thyroid function test was performed by after hospital admission and before PCI. Serum TSH, total triiodothyronine (TT3), total thyroxine (TT4), free triiodothyronine (FT3) and free thyroxine (FT4) levels were measured by chemiluminescence immunoassay. The reference intervals for thyroid function test were TT4, 78.43-157.40 $\mathrm{nmol} / \mathrm{L}$; TT3, $1.34-2.73 \mathrm{nmol} / \mathrm{L}$; TSH, 0.34-5.60 mIU/L; FT3, 3.80-6.00 pmol/L; FT4, 7.90-14.40 pmol/L. Euthyroidism (ET) was defined as all circulating level of TSH, FT3, FT4, TT3 and TT4 in the normal range. Subclinical hypothyroidism $(\mathrm{SCH})$ was defined as $\mathrm{TSH}>5.60 \mathrm{mIU} /$ L, with FT3, FT4, TT3 and TT4 in the normal range, without symptoms or signs of hypothyroidism.

\section{Statistical analysis}

Continuous variables were expressed as mean \pm standard deviation when normally distributed and as medians with inter quartile ranges for results not normally distributed. Categorical variables were presented as frequencies. Baseline clinical, laboratory, medication and PCI data between groups were compared using unpaired Student's t-test or Mann-Whitney U test for continuous variables and chi-square test or Fisher exact test for categorical variables. Kaplan-Meier survival curves associated with subclinical hypothyroidism and euthyroidism were compared with log-rank test. Multivariable Cox proportional hazards regression analysis was performed to estimate hazard ratios (HR) for all-cause death and cardiac death. We calculated multivariate HRs by adjusting for age, gender, body mass index, hypertension, diabetes mellitus, hyperlipidemia, smoking, family history of coronary artery disease, history of myocardial infarction, history of percutaneous coronary intervention, history of the coronary artery bypass graft, history of stroke, history of heart failure, history of renal failure, acute myocardial infarction, left ventricle ejection fraction, hemoglobin, fasting glucose, creatinine, total cholesterol, triglyceride, low density lipoprotein cholesterol, high density lipoprotein cholesterol, high-sensitivity Creactive protein, aspirin, clopidogrel, ß-Blocker, angiotensin II coenzyme inhibitor, angiotensin II receptor blocker, statins, multi-vessel disease, left main, left anterior descending, left circumflex artery, right coronary artery. A 2 -sided analysis with a $P$ value $<0.05$ was considered significant. All analyses were performed using the SPSS software program, version25 (IBM Corp. Released 2017. IBM SPSS Statistics for Windows, Version 25.0. Armonk, NY: IBM Corp.) 


\section{Results}

\section{Patients characteristics}

The cohort consisted of 3168 older patients who underwent PCI. Of the 3168 patients, 10.1\% $(n=320)$ had $\mathrm{SCH}, 89.9 \%(n=2848)$ had ET. The baseline clinical, biological and medication characteristics are summarized in Table 1. Compared with the patients with ET, $\mathrm{SCH}$ was more common in female patients and patients with hyperlipidemia, and it was associated with higher body mass index, lower hemoglobin level, higher serum total cholesterol, triglyceride, low density lipoprotein levels and lower high-density lipoprotein level. Frequency of antianginal drugs, antiplatelet agents and lipid lowering medicine was similar between the two groups. The angiographic and PCI data are shown in Table 2. There were no significant differences in the extent of diseased vessels, targeted vessel distribution, and number of stents between the two groups.

\section{Association between $\mathrm{SCH}$ and mortality}

Among the 3168 patients, 227 patients died during 4year follow-up. Of these, 29 were in $\mathrm{SCH}$ group and 198 in ET group. Among the 227 died patients, 124 patients died of cardiac cause. Cardiac death was 16 in the $\mathrm{SCH}$ group and 108 in the ET group. The 4-year cumulative all-cause mortality rates in patients with $\mathrm{SCH}$ and $\mathrm{ET}$ were 9.1 and $7.0 \%$ respectively. The 4-year cumulative cardiac mortality rates in patients with $\mathrm{SCH}$ and $\mathrm{ET}$ were 5.0 and $3.8 \%$ respectively. The Kaplan-Meier analysis showed that there was no significant difference in the all-cause mortality and cardiac mortality between patients with SCH and ET (Fig. 2 and Fig. 3).

\section{Relative risks for all-cause and cardiac death in patients with $\mathrm{SCH}$ vs. ET}

Table 3 and Table 4 summarized the relative risks for all-cause and cardiac death in patients with $\mathrm{SCH}$ vs. ET. Compared with ET, SCH was not associated with higher risk of all-cause and cardiac death. Adjusted for age, gender, body mass index, hypertension, diabetes mellitus, hyperlipidemia, smoking, et al., compared with ET, $\mathrm{SCH}$ was not associated with a higher risk of all-cause and cardiac death in subgroup of different age, gender and TSH level.

\section{Discussions}

In this large cohort of older patients aged 65 years or older undergoing $\mathrm{PCI}, \mathrm{SCH}$ was not associated with increased risks of all-cause and cardiac mortality. The prognostic significance of $\mathrm{SCH}$ applied equally to the subgroup of different gender, age and thyroid function level. These results suggested that $\mathrm{SCH}$ may not confer the detrimental effect on older patients undergoing PCI.
The prevalence of $\mathrm{SCH}$ increases with age. In the present study, the prevalence of $\mathrm{SCH}$ was $10.1 \%$, which was similar to previous studies [9]. $\mathrm{SCH}$ is associated with cardiovascular risk factors and metabolic syndrome [15]. A higher level of TSH has been related to increased BMI and hyperlipidemia [15]. Consistently, in the present study, we observed that patients with $\mathrm{SCH}$ have significant increases in BMI, serum level of TC, TG and LDL-C, which may explain why the patients in the SCH group received PCI at a younger age, comparing the ET group. As shown previously, $\mathrm{SCH}$ was more prevalent in female. In this cohort, women accounted for $58.1 \%$ in the $\mathrm{SCH}$ group. Also, the level of hemoglobin of patients with $\mathrm{SCH}$ was lower than that of patients with ET, which might be due to the higher female-to-male ratio in patients with $\mathrm{SCH}$.

There are only a few studies on the relationship between $\mathrm{SCH}$ and mortality in the elderly. The prognostic significance of $\mathrm{SCH}$ in the elderly is controversial. Several studies reported no association of $\mathrm{SCH}$ with death from cardiovascular or all-cause mortality in the elderly $[12,13]$. The Leiden $85+$ study revealed that $\mathrm{SCH}$ was associated with decreased all-cause mortality and cardiovascular mortality [10]. In contrast, a recent retrospective study by Grossman et al. demonstrated that $\mathrm{SCH}$ is associated with increased mortality in the elderly [11]. A recent review reported that $\mathrm{SCH}$ was not associated with increased risk of cardiovascular mortality or total mortality in the elderly [16]. However, owing to the relatively few studies, the result should be interpreted carefully and confirmed by further studies. To date, most of the findings in the elderly were derived from the general population. Although $\mathrm{SCH}$ has been associated with an increased risk of mortality in patients with established cardiovascular disease $[17,18]$, it is ambiguously defined whether $\mathrm{SCH}$ increases the risk of mortality in older patients with established cardiovascular disease.

To date, only a few studies evaluated the special association of $\mathrm{SCH}$ with mortality in patients with a high risk of ischemic heart disease. A recent study by Zhang reported an association between $\mathrm{SCH}$ defined based on serum TSH level and major adverse cardiovascular and cerebral events in patients treated with PCI [19]. The results showed that cardiac death was significantly higher in patients with $\mathrm{SCH}$ compared with patients with ET. This finding was obtained in a population with a mean age of 64.6 years. Another recent study found that $\mathrm{SCH}$ defined based on serum TSH and FT4 levels was associated with cardiovascular events and cardiac death in patients following PCI [20]. In this study, unlike previous studies without restriction on age, we have evaluated a large cohort of patients aged 65 years or older treated with PCI and followed their mortality risk up to 4 years after PCI. In the present study, we defined $\mathrm{SCH}$ based 
Table 1 Baseline clinical, biological, and medication characteristics

\begin{tabular}{|c|c|c|c|}
\hline & $\begin{array}{l}\mathrm{SCH} \\
(n=320)\end{array}$ & $\begin{array}{l}\text { ET } \\
(n=2848)\end{array}$ & $P$ Value \\
\hline \multicolumn{4}{|l|}{ Clinical characteristics } \\
\hline Age, years & $70.4 \pm 4.0$ & $70.9 \pm 4.2$ & 0.038 \\
\hline Female, n (\%) & $186(58.1)$ & $1152(40.4)$ & 0.000 \\
\hline $\mathrm{BMI}, \mathrm{kg} / \mathrm{m}^{2}$, & $26.4 \pm 3.2$ & $25.5 \pm 3.0$ & 0.000 \\
\hline Hypertension, n (\%) & $248(77.5)$ & $2128(74.7)$ & 0.276 \\
\hline Diabetes mellitus, n (\%) & $100(31.3)$ & $932(32.7)$ & 0.594 \\
\hline Hyperlipidemia, n (\%) & $174(54.4)$ & $1306(45.9)$ & 0.004 \\
\hline Current smoking, n (\%) & $58(18.1)$ & $572(20.1)$ & 0.405 \\
\hline Family history of CAD, n (\%) & $16(5.0)$ & $174(6.1)$ & 0.428 \\
\hline History of Ml, n (\%) & $28(8.8)$ & $352(12.4)$ & 0.060 \\
\hline History of $\mathrm{PCl}, \mathrm{n}(\%)$ & $44(13.8)$ & $496(17.4)$ & 0.098 \\
\hline History of CABG, n (\%) & $4(1.3)$ & $74(2.6)$ & 0.140 \\
\hline History of Stroke, n (\%) & $36(11.3)$ & $358(12.6)$ & 0.497 \\
\hline History of HF, n (\%) & $26(8.1)$ & $177(6.2)$ & 0.186 \\
\hline History of RF, n (\%) & $12(3.8)$ & $136(4.8)$ & 0.410 \\
\hline SAP, n (\%) & $40(12.5)$ & $414(14.5)$ & 0.324 \\
\hline UAP, n (\%) & $216(67.5)$ & $1928(67.7)$ & 0.943 \\
\hline AMI, n (\%) & $64(20.0)$ & $506(17.8)$ & 0.324 \\
\hline LVEF, (\%) & $63.6 \pm 7.8$ & $63.0 \pm 9.1$ & 0.265 \\
\hline \multicolumn{4}{|l|}{ Laboratory characteristics } \\
\hline TSH & $7.19(6.20-8.28)$ & $1.64(1.10-2.46)$ & 0.000 \\
\hline FT3 & $4.80(4.20-5.40)$ & $4.90(4.30-5.40)$ & 0.301 \\
\hline FT4 & $11.00(9.33-12.80)$ & $11.00(9.40-12.70)$ & 0.879 \\
\hline Hemoglobin, g/dl & $129(123,142)$ & $137(127,147)$ & 0.000 \\
\hline Fasting glucose, $\mathrm{mmol} / \mathrm{L}$ & $5.57(5.03,6.49)$ & $5.62(5.09,6.51)$ & 0.478 \\
\hline Creatinine, $\mu \mathrm{mol} / \mathrm{L}$ & $74.5(62.0,89.0)$ & $76.0(65.0,89.0)$ & 0.206 \\
\hline $\mathrm{TC}, \mathrm{mmol} / \mathrm{L}$ & $4.50(4.04,5.15)$ & $4.30(3.64,5.01)$ & 0.000 \\
\hline $\mathrm{TG}, \mathrm{mmol} / \mathrm{L}$ & $1.50(1.56,1.97)$ & $1.39(1.03,1.88)$ & 0.002 \\
\hline $\mathrm{LDL}-\mathrm{C}, \mathrm{mmol} / \mathrm{L}$ & $2.61(2.25,3.11)$ & $2.58(2.01,3.11)$ & 0.018 \\
\hline $\mathrm{HDL}-\mathrm{C}, \mathrm{mmol} / \mathrm{L}$ & $1.14(1.01,1.34)$ & $1.09(0.94,1.26)$ & 0.000 \\
\hline $\mathrm{HsCRP}, \mathrm{mg} / \mathrm{L}$ & $2.00(0.71,4.83)$ & $1.75(0.69,4.60)$ & 0.221 \\
\hline \multicolumn{4}{|l|}{ Medications at discharge } \\
\hline Aspirin, n (\%) & $318(99.4)$ & $2842(99.8)$ & 0.416 \\
\hline Clopidogrel, n (\%) & $318(99.4)$ & $2843(99.8)$ & 0.319 \\
\hline ß-Blocker, n (\%) & $256(80.0)$ & $2200(77.2)$ & 0.263 \\
\hline ACEI/ARB, n (\%) & $174(54.4)$ & $1562(54.8)$ & 0.873 \\
\hline Calcium channel antagonist, n (\%) & $102(31.9)$ & $796(27.9)$ & 0.140 \\
\hline Nitrates, n (\%) & $198(61.9)$ & $1866(65.5)$ & 0.195 \\
\hline Statins, n (\%) & $308(96.3)$ & $2732(95.9)$ & 0.781 \\
\hline
\end{tabular}

Data are expressed as mean $\pm S D$, medians with inter quartile ranges or percentage. $B M I$ body mass index, $C A D$ coronary artery disease, $M I$ myocardial infarction, $P C l$ percutaneous coronary intervention, $C A B G$ coronary artery bypass graft, $H F$ hear failure, $R F$ renal failure, $S A P$ stable angina pectoris, UAP unstable angina pectoris, $A M I$ acute myocardial infarction, $L V E F$ left ventricle ejection fraction, $T C$ total cholesterol, TG triglyceride, $L D L-C$ low density lipoprotein cholesterol, HDL-C high density lipoprotein cholesterol, HsCRP high-sensitivity C-reactive protein, ACE-I angiotensin II coenzyme inhibitor, ARB angiotensin II receptor blocker 
Table 2 Baseline angiographic and PCl characteristics

\begin{tabular}{llll}
\hline & $\begin{array}{l}\text { SCH } \\
(\boldsymbol{n}=\mathbf{3 2 0})\end{array}$ & $\begin{array}{l}\text { ET } \\
(\boldsymbol{n}=\mathbf{2 8 4 8})\end{array}$ & P Value \\
\hline Diseased vessels & & & \\
1-vessel, n (\%) & $82(25.6)$ & $870(30.5)$ & 0.069 \\
2-vessel, n (\%) & $100(31.3)$ & $836(29.4)$ & 0.481 \\
3-vessel, n (\%) & $138(43.1)$ & $1142(40.1)$ & 0.348 \\
Multi-vessel disease, n (\%) & $238(74.4)$ & $1978(69.5)$ & 0.069 \\
Target vessel & & & \\
LM, n (\%) & $8(2.5)$ & $126(4.4)$ & 0.105 \\
LAD, n (\%) & $174(54.4)$ & $1700(59.7)$ & 0.067 \\
LCX, n (\%) & $92(28.8)$ & $846(29.7)$ & 0.723 \\
RCA, n (\%) & $137(42.8)$ & $1128(39.6)$ & 0.267 \\
Number of stents & $1.8 \pm 1.0$ & $1.8 \pm 1.0$ & 0.898 \\
Drug-eluting stent, n (\%) & $320(100)$ & $2848(100)$ & 1.000
\end{tabular}

Data are expressed as percentage. $L M$ left main, $L A D$ left anterior descending, $L C X$ left circumflex artery, $R C A$ right coronary artery

on TSH, TT4, TT3, FT3, and FT4 levels to eliminate possible misclassification of $\mathrm{SCH}$. We observed that there was no significant difference in mortality in elderly patients with $\mathrm{SCH}$ compared with patients with ET. In comparison with ET, $\mathrm{SCH}$ was not associated with a higher risk of all-cause and cardiac death. After adjustment for baseline variables, the prognostic significance of SCH applied equally to subgroups of different gender, different age and different degree of thyroid-stimulating hormone level. Our results suggest that $\mathrm{SCH}$ may not an independent risk factor for mortality in older patients undergoing PCI. The increase of serum TSH observed in the elderly may represent a physiological process reflecting a certain degree down-regulation hypothalamuspituitary-thyroid-peripheral (HPTP) axis. Therefore,
$\mathrm{SCH}$, especially mild elevation of TSH, should not be regarded as a pathological condition in older patients undergoing PCI. Moreover, we focused end point on death to fully assess the impact of $\mathrm{SCH}$ on mortality in patients underwent PCI.

The association between $\mathrm{SCH}$ and mortality has been well established in young individuals [21]. SCH is associated with many well-known cardiovascular risk factors. However, we could not demonstrate the negative effect of $\mathrm{SCH}$ on mortality in older patients undergoing PCI. The presence of multiple morbidities in the elderly may contribute to the results. There are also several potential explanations for this neutral finding. First, the elderly patients and patients with $\mathrm{SCH}$ have common pathophysiological conditions. Additional assessment of serum TSH level adds little to the prediction ability of common risk scoring models, attesting to the fact that the mortality associated with $\mathrm{SCH}$ may be caused by traditional cardiovascular risk factors [22]. Thus these cardiovascular risk factors for CHD among those elderly patients undergoing PCI may overshadow the negative effect of $\mathrm{SCH}$ on cardiovascular system. Second, an interaction between age and $\mathrm{SCH}$ cannot be refuted. A recent cohort study on 80,490 persons found that the association between $\mathrm{SCH}$ between all-cause or vascular mortality was stronger in men below 60 years compared to older males [23]. Another meta-analysis showed that the risk of the cardiovascular and all-cause mortality is higher in those mean age $<65$ years than for those of average age $\geq 65$ years [16]. All these results suggest that there may be age-related mortality difference associated with $\mathrm{SCH}$, with stronger association in younger patients that attenuated advancing age. In addition, the current evidence to make a recommendation for levothyroxine therapy is not strong. Levothyroxine treatment in

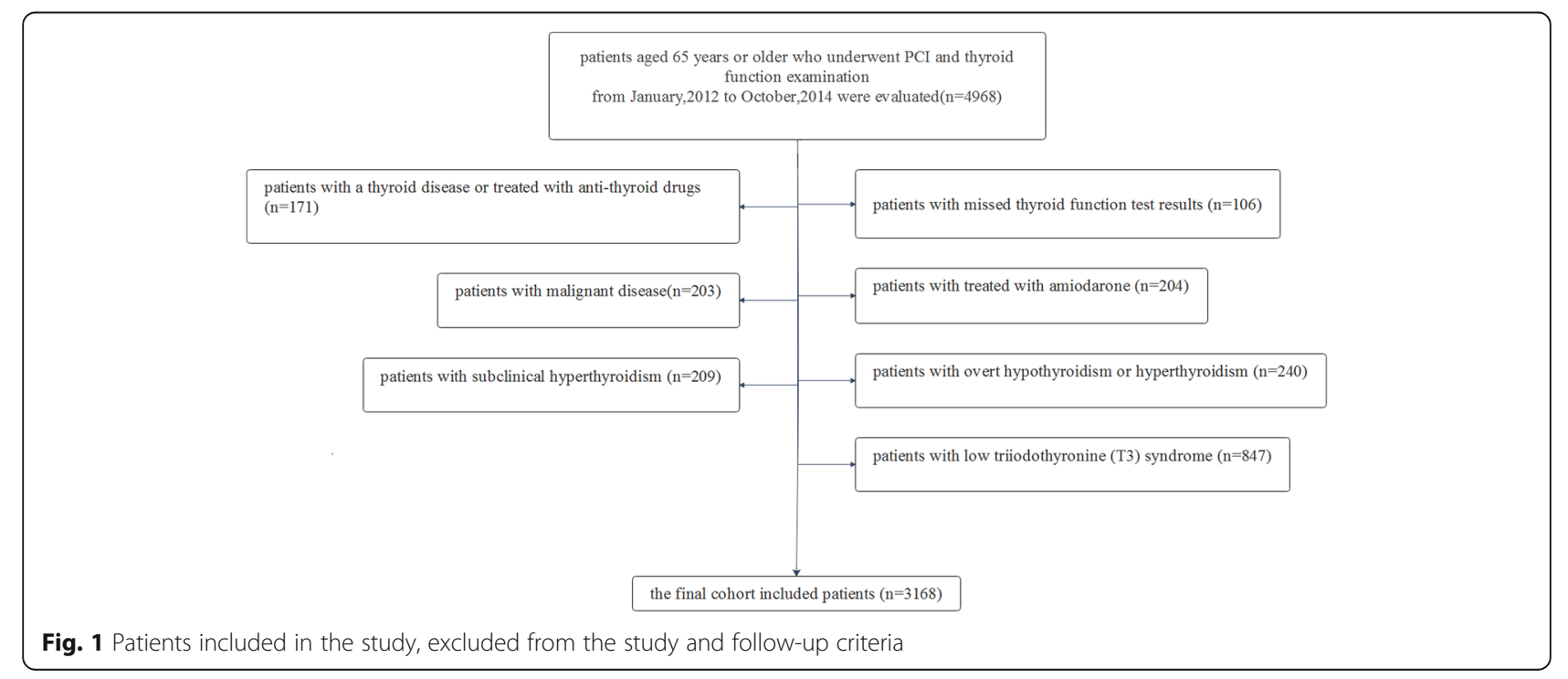




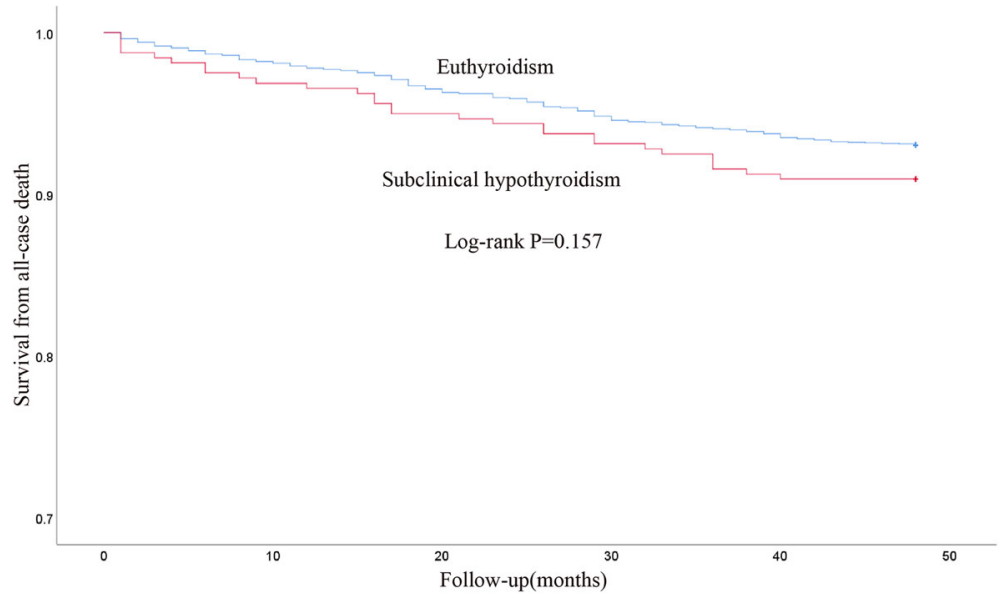

Fig. 2 Kaplan-Meier survival curves for all-cause death for patients with SCH and ET

patients with $\mathrm{SCH}$ and established heart disease was not associated with a significant benefit for the risk of allcause mortality [24]. A recent prospective study found no beneficial effect of treatment with levothyroxine in older adults [25]. Moreover, another study reported that treatment with levothyroxine was associated with excess mortality in individuals 65 years or older with $\mathrm{SCH}$ [26]. Taken together, it is suggested that $\mathrm{SCH}$ may not have negative impact on mortality in the elderly.

\section{Limitations}

The present study has several limitations. First, the present study was a single-center retrospective study, and replication is needed to assess the validity of the findings, although the number of the patients analyzed in the present study are large. Second, thyroid function test was only performed at baseline, and the influences of medication treatments on thyroid function and the natural history of $\mathrm{SCH}$ were not investigated. However, compared with previous studies, we simultaneously measured serum FT3, FT3, T3, T4 and TSH levels. We defined $\mathrm{SCH}$ strictly. Therefore, the present study truly reflected the effect of $\mathrm{SCH}$ on mortality in older patients after PCI. Moreover, previous study did not demonstrate increased risk of cardiovascular death in older adult with persistent SCH [12]. Third, previous studies revealed that $\mathrm{SCH}$ in patients with an acute cardiac disease have been associated with increased risk of death. Due to the limited number of patients, we did not make subgroup analysis according to the clinical presentation. Thyroxine in acute myocardial infarction study will clarify the association of thyroid function at the time of AMI with cardiovascular outcomes [27]. Finally, our study revealed no increased risk of mortality in patients with $\mathrm{TSH} \geq 10$ $\mathrm{mIU} / \mathrm{L}$. The small sample size with $\mathrm{TSH} \geq 10 \mathrm{mIU} / \mathrm{L}$ may weaken the reliability of the result. Therefore, the

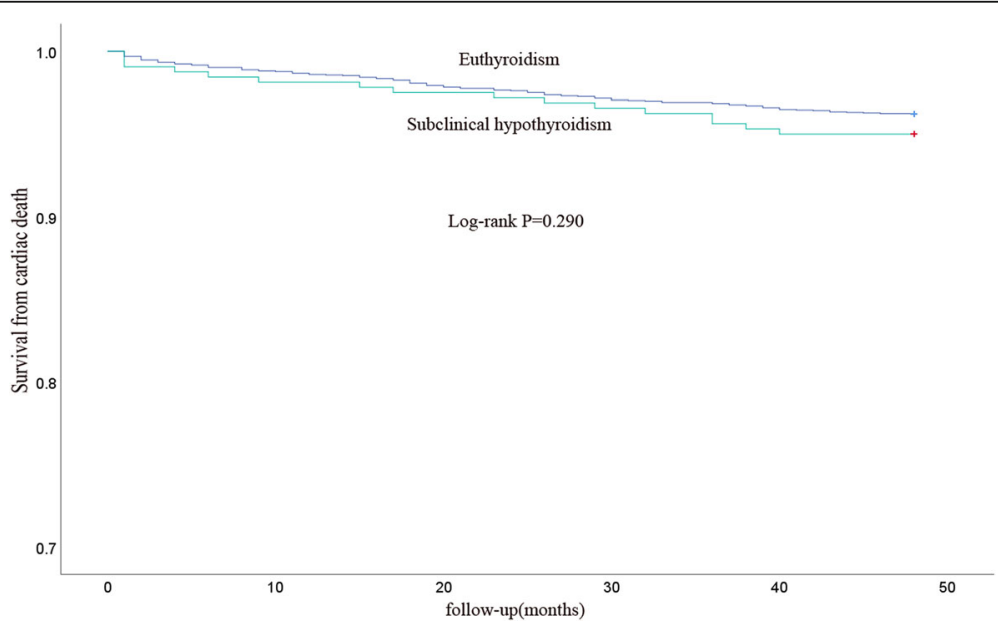

Fig. 3 Kaplan-Meier survival curves for cardiac death for patients with SCH and ET 
Table 3 Relative risks for all-cause death in patients with SCH vs. ET

\begin{tabular}{|c|c|c|c|c|c|c|c|c|}
\hline & Death(n) & Number at risk(n) & Unadjusted RR & $95 \% \mathrm{Cl}$ & $P$ Value & Adjusted RR & $95 \% \mathrm{Cl}$ & $P$ Value \\
\hline$\overline{E T}$ & 198 & 2848 & 1.000 (reference) & & & 1.000 (reference) & & \\
\hline $\mathrm{SCH}$ & 29 & 320 & 1.323 & $0.896-1.954$ & 0.159 & 1.261 & $0.802-1.982$ & 0.315 \\
\hline \multicolumn{9}{|l|}{ Age $<75$ years } \\
\hline ET & 159 & 2276 & 1.000 & & & 1.000 & & \\
\hline $\mathrm{SCH}$ & 25 & 268 & 1.356 & $0.889-2.067$ & 0.157 & 1.261 & $0.767-2.074$ & 0.360 \\
\hline \multicolumn{9}{|c|}{ Age $\geq 75$ years } \\
\hline ET & 39 & 572 & 1.000 & & & 1.000 & & \\
\hline $\mathrm{SCH}$ & 4 & 52 & 1.138 & $0.407-3.185$ & 0.805 & 0.295 & $0.029-2.963$ & 0.300 \\
\hline \multicolumn{9}{|l|}{ Male } \\
\hline ET & 124 & 1696 & 1.000 & & & 1.000 & & \\
\hline $\mathrm{SCH}$ & 12 & 132 & 1.248 & $0.690-2.256$ & 0.464 & 1.037 & $0.523-2.058$ & 0.917 \\
\hline \multicolumn{9}{|l|}{ Female } \\
\hline ET & 74 & 1152 & 1.000 & & & 1.000 & & \\
\hline $\mathrm{SCH}$ & 17 & 186 & 1.444 & $0.852-2.446$ & 0.172 & 1.016 & $0.500-2.065$ & 0.965 \\
\hline \multicolumn{9}{|l|}{ TSH } \\
\hline $0.34-5.60$ & 198 & 2848 & 1.000 & & & 1.000 & & \\
\hline $5.61-9.99$ & 24 & 278 & 1.255 & $0.822-1.918$ & 0.293 & 1.275 & $0.767-2.121$ & 0.349 \\
\hline$\geq 10$ & 5 & 42 & 1.749 & $0.720-4.248$ & 0.217 & 1.062 & $0.322-3.497$ & 0.921 \\
\hline
\end{tabular}

Adjusted RR: adjusted for age, gender, body mass index, hypertension, diabetes mellitus, hyperlipidemia, smoking, family history of coronary artery disease, History of myocardial infarction, history of percutaneous coronary intervention, history of the coronary artery bypass graft, history of stroke, history of heart failure, History of renal failure, acute myocardial infarction, left ventricle ejection fraction, hemoglobin, fasting glucose, creatinine, total cholesterol, triglyceride, low density lipoprotein cholesterol, high density lipoprotein cholesterol, high-sensitivity C-reactive protein, aspirin, clopidogrel, B-Blocker, angiotensin II coenzyme inhibitor, angiotensin II receptor blocker, statins, multi-vessel disease, left main, left anterior descending, left circumflex artery, right coronary artery

Table 4 Relative risks for cardiac death in patients with SCH vs. ET

\begin{tabular}{|c|c|c|c|c|c|c|c|c|}
\hline & Death(n) & Number at risk(n) & Unadjusted RR & $95 \% \mathrm{Cl}$ & $P$ Value & Adjusted RR & $95 \% \mathrm{Cl}$ & $P$ Value \\
\hline$\overline{\mathrm{ET}}$ & 108 & 2848 & 1.000 (reference) & & & 1.000 (reference) & & \\
\hline $\mathrm{SCH}$ & 16 & 320 & 1.326 & $0.785-2.242$ & 0.292 & 1.231 & $0.650-2.334$ & 0.524 \\
\hline \multicolumn{9}{|l|}{ Age $<75$ years } \\
\hline ET & 83 & 2276 & 1.000 & & & 1.000 & & \\
\hline $\mathrm{SCH}$ & 14 & 268 & 1.445 & $0.820-2.545$ & 0.203 & 1.304 & $0.639-2.661$ & 0.467 \\
\hline \multicolumn{9}{|c|}{ Age $\geq 75$ years } \\
\hline ET & 25 & 572 & 1.000 & & & 1.000 & & \\
\hline $\mathrm{SCH}$ & 2 & 52 & 0.876 & $0.208-3.700$ & 0.858 & 0.762 & $0.324-1.678$ & 0.938 \\
\hline \multicolumn{9}{|l|}{ Male } \\
\hline ET & 73 & 1696 & 1.000 & & & 1.000 & & \\
\hline $\mathrm{SCH}$ & 7 & 132 & 1.225 & $0.564-2.661$ & 0.607 & 0.917 & $0.351-2.397$ & 0.860 \\
\hline \multicolumn{9}{|l|}{ Female } \\
\hline ET & 35 & 1152 & 1.000 & & & 1.000 & & \\
\hline $\mathrm{SCH}$ & 9 & 186 & 1.602 & $0.770-3.333$ & 0.207 & 1.0000 & $0.348-2.870$ & 1.000 \\
\hline \multicolumn{9}{|l|}{ TSH } \\
\hline $0.34-5.60$ & 108 & 2848 & 1.000 & & & 1.000 & & \\
\hline $5.61-9.99$ & 13 & 278 & 1.238 & $0.696-2.201$ & 0.467 & 1.054 & $0.508-2.187$ & 0.887 \\
\hline$\geq 10$ & 3 & 42 & 1.934 & $0.614-6.092$ & 0.260 & 1.321 & $0.274-6.358$ & 0.729 \\
\hline
\end{tabular}

Adjusted RR: adjusted for age, gender, body mass index, hypertension, diabetes mellitus, hyperlipidemia, smoking, family history of coronary artery disease, History of myocardial infarction, history of percutaneous coronary intervention, history of coronary artery bypass graft, history of stroke, history of heart failure, History of renal failure, acute myocardial infarction, left ventricle ejection fraction, hemoglobin, fasting glucose, creatinine, total cholesterol, triglyceride, low density lipoprotein cholesterol, high density lipoprotein cholesterol, high-sensitivity C-reactive protein, aspirin, clopidogrel, ß-Blocker, angiotensin II coenzyme inhibitor, angiotensin II receptor blocker, statins, multi-vessel disease, left main, left anterior descending, left circumflex artery, right coronary artery 
result needs to be further confirmed in large prospective studies.

\section{Conclusions}

$\mathrm{SCH}$ on admission was not associated with higher risk of all-cause death and cardiac death in older patients undergoing PCI. Our results suggest that $\mathrm{SCH}$ does not represent a risk factor for morality in patients aged 65 or older undergoing PCI.

\section{Abbreviations}

SCH: Subclinical hypothyroidism; PCl: Percutaneous coronary intervention; ET: Euthyroidism; RRs: Relative risks; TSH: Thyroid-stimulating hormone; CVD: Cardiovascular disease; TT3: Total triiodothyronine; TT4: Total thyroxine; FT3: Free triiodothyronine; FT4: Free thyroxine; ET: Euthyroidism; BMI: Body mass index; CAD: Coronary artery disease; MI: Myocardial infarction; CABG: Coronary artery bypass graft; HF: Hear failure; RF: Renal failure; SAP: Stable angina pectoris; UAP: Unstable angina pectoris; AMI: Acute myocardial infarction; LVEF: Left ventricle ejection fraction; TC: Total cholesterol; TG: Triglyceride; LDL-C: Low density lipoprotein cholesterol; HDLC: High density lipoprotein cholesterol; HsCRP: High-sensitivity C-reactive protein; ACE-I: Angiotensin II coenzyme inhibitor; ARB: Angiotensin II receptor blocker; LM: Left main; LAD: Left anterior descending; LCX: Left circumflex artery; RCA: Right coronary artery

\section{Acknowledgements}

We declare that all the authors have no conflict of interest. This study was supported by the grant from Hebei Science and technology support project (to MQ ZHENG, 19277757D).

\section{Authors' contributions}

Liu $Y$, Wei $M$ and Wang $L$ developed the idea of the study, participated in its design and coordination and helped to draft the manuscript. Liu G, Ma G, Ono K, Cao Z, and Yang M contributed to the acquisition and interpretation of data. Zheng M provided critical review and substantially revised the manuscript. All authors read and approved the final manuscript.

\section{Funding}

There is no funding or sponsors in the study design, collection, analysis, interpretation of data, he writing of the manuscript and the decision to submit the manuscript for publication.

\section{Availability of data and materials}

The raw/processed data required to reproduce these findings cannot be shared for now, because these data are part of ongoing follow-up studies. The datasets used and analysed during the current study are available from the corresponding author on reasonable request.

\section{Ethics approval and consent to participate}

The study was approved by the ethics committee of The First Hospital of Hebei Medical University. All patients provided written informed consent. Reference number: 20190438.

\section{Consent for publication}

Written informed consent for publication was obtained from all participants.

\section{Competing interests}

The authors declare that they have no competing interests.

\section{Author details}

${ }^{1}$ Heart Center, The First Hospital of Hebei Medical University, No.89 Donggang Road, Shijiazhuang 050031, Hebei, China. ${ }^{2}$ Department of Cardiology, Tianjin Chest Hospital, Tianjin 300222, China. ${ }^{3}$ Department of Pathophysiology, Oita University School of Medicine, Yufu, Oita 879-5593, Japan.
Received: 23 June 2020 Accepted: 18 February 2021

Published online: 05 March 2021

\section{References}

1. Shanmugam VB, Harper R, Meredith I, Malaiapan Y, Psaltis PJ. An overview of $\mathrm{PCl}$ in the very elderly. J Geriatr Cardiol. 2015;12:174-84. https://doi.org/1 0.11909/j.issn.1671-5411.2015.02.012.

2. Vandermolen S, Abbott J, De Silva K. What's age got to do with it? A review of contemporary revascularization in the elderly. Curr Cardiol Rev. 2015;11: 199-208.

3. Ye Y, Xie H, Zeng Y, Zhao X, Tian Z, Zhang S, et al. Association between subclinical hypothyroidism and blood pressure-a meta-analysis of observational studies. Endocr Pract. 2014;20:150-8.

4. Pearce EN. Update in lipid alterations in subclinical hypothyroidism. J Clin Endocrinol Metab. 2012;97:326-33.

5. Masaki M, Komamura K, Goda A, Hirotani S, Otsuka M, Nakabo A, et al. Elevated arterial stiffness and diastolic dysfunction in subclinical hypothyroidism. J Circ J. 2014;78(6):1494-500.

6. Razvi S, Weaver JU, Pearce SH. Subclinical thyroid disorders: significance and clinical impact. J Clin Pathol. 2010;63:379-86.

7. Biondi B, Cooper DS. The clinical significance of subclinical thyroid dysfunction. Endocr Rev. 2008;29:76-131.

8. Marfella R, Ferraraccio F, Rizzo MR, Portoghese M, Barbieri M, Basilio C, et al. Innate immune activity in plaque of patients with untreated and Lthyroxine-treated subclinical hypothyroidism. J Clin Endocrinol Metab. 2011 Apr;96:1015-20.

9. Floriani C, Gencer B, Collet TH, Rodondi N. Subclinical thyroid dysfunction and cardiovascular diseases: 2016 update. Eur Heart J. 2017 . 39(7):503-7.

10. Gussekloo J, van Exel E, de Craen AJ, Meinders AE, Frölich M, Westendorp RG. Thyroid status, disability and cognitive function, and survival in old age. JAMA. 2004;292:2591-9.

11. Grossman A, Weiss A, Koren-Morag N, Shimon I, Beloosesky Y, Meyerovitch J. Subclinical thyroid disease and mortality in the elderly: a retrospective cohort study. Am J Med. 2016:129:423-30.

12. Hyland KA, Arnold AM, Lee JS, Cappola AR. Persistent subclinical hypothyroidism and cardiovascular risk in the elderly: the cardiovascular health study. J Clin Endocrinol Metab. 2013;98:533-40.

13. Waring AC, Harrison S, Samuels MH, Ensrud KE, LeBlanc ES, Hoffman AR, et al. Osteoporotic fractures in men (MrOS) study. Thyroid function and mortality in older men: a prospective study. J Clin Endocrinol Metab. 2012; 97:862-70.

14. Pearce SHS, Razvi S, Yadegarfar ME, Martin-Ruiz C, Kingston A, Collerton J, et al. Serum thyroid function, mortality and disability in advanced old age: the Newcastle 85+ study. J Clin Endocrinol Metab. 2016;101:4385-94.

15. Suh S, Kim DK. Subclinical Hypothyroidism and Cardiovascular Disease. Endocrinol Metab (Seoul). 2015;30:246-51.

16. Sun J, Yao L, Fang Y, Yang R, Chen Y, Yang K, et al. Relationship between subclinical thyroid dysfunction and the risk of cardiovascular outcomes: a systematic review and Meta-analysis of prospective cohort studies. Int J Endocrinol. 2017. https://doi.org/10.1155/2017/8130796.

17. lervasi G, Molinaro S, Landi P, Taddei MC, Galli E, Mariani F, et al. Association between increased mortality and mild thyroid dysfunction in cardiac patients. Arch Intern Med. 2007:167:1526-32.

18. Molinaro S, lervasi G, Lorenzoni V, Coceani M, Landi P, Srebot V, et al. Persistence of mortality risk in patients with acute cardiac diseases and mild thyroid dysfunction. Am J Med Sci. 2012;343:65-70.

19. Zhang M, Sara JD, Matsuzawa Y, Gharib H, Bell MR, Gulati R, et al. Clinical outcomes of patients with hypothyroidism undergoing percutaneous coronary intervention. Eur Heart J. 2016:37:2055-65.

20. Lee $Y$, Lim YH, Shin JH, Park J, Shin J. Impact of subclinical hypothyroidism on clinical outcomes following percutaneous coronary intervention. Int J Cardiol. 2018:253:155-60.

21. Razvi S, Shakoor A, VanderpumpM WJU, Pearce SHS. The influence of age on the relationship between subclinical hypothyroidism and ischemic heart disease: a meta- analysis. J Clin EndocrinolMetab. 2008;93:2998-3007.

22. Kim TH, Choi HS, Bae JC, Moon JH, Kim HK, Choi SH, et al Subclinical hypothyroidism in addition to common risk scores for prediction of cardiovascular disease: a 10-year community-based cohort study. Eur J Endocrinol. 2014;171:649-57. 
23. Kovar FM, Fang IF, Perkmann T, Haslacher H, Slavka G, Födinger M, et al. Subclinical hypothyroidism and mortality in a large Austrian cohort: a possible impact on treatment? Wien Klin Wochenschr. 2015;127:924-30.

24. Andersen MN, Olsen AS, Madsen JC, Kristensen SL, Faber J, Torp-Pedersen C, et al. Long-term outcome in levothyroxine treated patients with subclinical hypothyroidism and concomitant heart disease. J Clin Endocrinol Metab. 2016;101:4170-7.

25. Shah R. In older adults with subclinical hypothyroidism, levothyroxine did not improve symptoms or tiredness. Ann Intern Med. 2017;167:JC14.

26. Grossman A, Feldhamer I, Meyerovitch J. Treatment with levothyroxin in subclinical hypothyroidism is associated with increased mortality in the elderly. Eur J Intern Med. 2018. https://doi.org/10.1016/j.ejim.2017.11.010.

27. Jabbar A, Ingoe L, Pearce S, Zaman A, Razvi S. Thyroxine in acute myocardial infarction (ThyrAMI)-levothyroxine in subclinical hypothyroidismpost-acute myocardial infarction: study protocol for a randomised controlled trial. Trials. 2015. https://doi.org/10.1186/s13063-0150621-5.

\section{Publisher's Note}

Springer Nature remains neutral with regard to jurisdictional claims in published maps and institutional affiliations.

Ready to submit your research? Choose BMC and benefit from:

- fast, convenient online submission

- thorough peer review by experienced researchers in your field

- rapid publication on acceptance

- support for research data, including large and complex data types

- gold Open Access which fosters wider collaboration and increased citations

- maximum visibility for your research: over $100 \mathrm{M}$ website views per year

At $\mathrm{BMC}$, research is always in progress.

Learn more biomedcentral.com/submissions 